\title{
Exploration of the Methods of Establishing the Minimum Clinical Important Difference Based on Anchor and Its Application in the Quality of Life Measurement Scale QLICP-ES (V2.0) for Esophageal Cancer
}

\section{Dandan Ren}

Guangdong Medical University

\section{Ting Wu}

Guangdong Medical University

chonghua Wan ( $\nabla$ wanchh@hotmail.com )

Guangdong Medical University https://orcid.org/0000-0002-7323-6837

\section{Gaofeng Li}

Yunnan Tumor Hospital

\section{Yanbo Qi}

the Center for Disease Control and Prevention of Yunnan Province

\section{Yujing Fang}

Sun Yat-sen University Cancer Center

Jiudi Zhong

Sun Yat-sen University Cancer Center

\section{Research}

Keywords: Quality of life, Esophageal cancer, the minimum clinical important difference, Anchor-based method, ROC curve, Multiple linear regression model

Posted Date: September 2nd, 2020

DOI: https://doi.org/10.21203/rs.3.rs-58873/v1

License: (c) (1) This work is licensed under a Creative Commons Attribution 4.0 International License. Read Full License

Version of Record: A version of this preprint was published at Health and Quality of Life Outcomes on July 2nd, 2021. See the published version at https://doi.org/10.1186/s12955-021-01808-7. 


\section{Abstract}

Background: The development of the minimum clinical important difference (MCID) can make it easier for researchers or doctors to judge the significance of research results and the effect of intervention measures, and improve the evaluation system of efficacy. This paper is aimed to calculate the MCID based on anchor and to develop MCID for esophageal cancer scale (QLICP-ES).

Methods: Q29 of EORTC QLQ-C30 was used as the subjective anchor to calculate the score difference between each domain at discharge and admission. MCID was established according to two standards, "one grade difference" $(A)$ and "at least one grade difference" $(B)$, and developed by three methods: anchor-based method, ROC curve method and multiple linear regression model.

Results: Most of the correlation coefficients of Q29 and various domains of the QLICP-ES were higher than 0.30 . The rank of $\mathrm{MCID}$ values determined by different methods and standards were as follows: standard $B>$ standard A, anchor-based method $>$ ROC curve method $>$ multiple linear regression model. The recommended MCID values of physical domain, psychological domain, social domain, common symptom and side-effects domain, the specific domain and the overall of the QLICP-ES were 7.8, 9.7, 4.7, 3.6, 4.3, 2.3 and 2.9, respectively.

Conclusion: Different methods have their own advantages and disadvantages, and also different definitions and standards can be adopted according to research purposes and methods. A lot of different MCID values were presented in this paper so that it can be easy and convenient to select by users.

\section{Background}

Esophageal cancer is the second most common solid intrathoracic malignancy behind lung cancer and the sixth leading cause of cancer death in the world [1,2]. The incidence and death of esophageal cancer in China account for about $50 \%$ of the world's cases [3]. The proportion of male and female patients dying is about 2:1, and most of them are over 40 years old [4]. The typical symptom of esophageal cancer is progressive dysphagia, due to various treatments only to prolong survival, how to improve the quality of life (QOL) of patients becomes the concerning in field of medicine. Consequently, a lot of measuring instruments such as QOL/PRO and mental health scales have been developed and are widely used in clinical practices and researches.

However, the interpretation of the scores of the scale is usually judged by the $P$ value, more and more scholars have realized that it is not reasonable and scientific to judge the curative effect only according to the different scale scores before and after the treatments (hypothesis test $P$ values). In fact, the $P$ value will become statistically significant as the samples being big enough, which does not mean having clinical significance [5]. Therefore, a key question in the application of the scale is how much its score must change to be clinically meaningful, namely, the minimum clinical important difference (MCID).

There are different names and meanings for MCID: minimal important difference (MID) [6], minimal clinically important change (MCIC) [7], the smallest detectable difference (SDD), minimal detectable change (MDC) [8],

Loading [MathJax]/jax/output/CommonHTML/fonts/TeX/fontdata.js e several calculation standards with its name and 
standard having not been completely unified [10-13] : deterioration, a little deterioration, no change, a little improvement, improvement, etc.. There are several methods for the formulation of MCID, among which there are two traditional methods including anchor-based methods and distribution-based methods. Although the traditional methods have their advantages, their shortcomings and limitations are gradually exposed for there is no unified standard. All anchor-based approaches described by Crosby et al. [14] are limited in that they fail to take into account the variability of the instrument and/or the sample. The major disadvantage of all methods using the distribution-based approach is that they do not, in themselves, provide a good indication of the importance of the observed change[15].

In recent years, some new methods have been proposed such as ROC curve method based on anchor and multiple linear regression model[16, 17]. This paper is aimed to discuss in detail how to apply the classical anchor-based methods, especially the new methods in recent years, to formulate MCID for the Quality of Life Measurement Scale QLICP-ES (V2.0) for Esophageal Cancer, and to compare the values of MCID under different methods and standards. Here, the QLICP-ES (V2.0) is an QOL instrument for esophageal cancer under the system of QLICPs (Quality of Life Instruments for Cancer Patients) [8, 18], forming by a generic module QLICP-GM (V2.0) (including domains of physical function, psychological function, social functions, common symptoms and side effects) and an esophageal cancer specific module. The QLICPs is a Chinese QOL instruments system developed by module approach with a general module (QLICP-GM) being used with all types of cancer, and some specific modules for different cancers[19, 20].

\section{Methods}

\section{Survey Methods}

Patients with esophageal cancer who agreed to participate in this study and satisfied our inclusion criteria were investigated in Yunnan tumor hospital and cancer prevention center of Sun Yat-Sen University. The investigators (doctors/ nurses/medical postgraduates) explained the aim of the test and the scales to the patients. The Participating patients were required to finish the informed consent form and the scales of QLICP-ES (V2.0) and Chinese version of EORTC QLQ-C30 [21] independently on the day of admission to the hospital, and once again at the day before discharge.

The raw scores of items, domains and overall scale were calculated for the QLICP-ES according to the scoring guide, with each domain score being obtained by adding its own item score together and the overall score being the sum of five domains score. And all domains and the overall scores were linearly converted to a 0 100 scale standardized scores.

\section{Anchor-based Method}

The better method in formulation of MCID is anchor-based method, which was proposed by American scholar Lydick et al. [22] in 1993. Its principle is to clarify the meaning of the rating change of the scale by examining the relationship between the scale and the score of another independent measurement tool or other indinatare Firct on annronriato anchnr wase colontod and the correlation coefficient between the anchor and Loading [MathJax]/jax/output/CommonHTML/fonts/TeX/fontdata.js 
the test scale was reported. Revicki [12] et al. believed that the correlation coefficient should be no less than $0.30 \sim 0.35$. Second, MCID were calculated according to some standards defining the effects of treatments.

In this paper, the data were obtained from the self-matched experimental design, and the anchor-based method was mainly used to formulate the MCID of QLICP-ES. The 29th item of EORTC QLQ-C30, " Q29, how do you evaluate your overall health in the past week?", is used as the subjective anchor, with the answers including seven grades (from very poor to very good). Pearson correlation analysis was used to calculate the correlation coefficients between Q29 and various domains. The two effects standards of "one grade difference" and "at least one grade difference" were selected to develop MCID, ie. the same anchor scores differ one grade after the intervention (including the rise and fall of a level), at least one grade (including the rise and fall of one or more levels).

If represents respondents baseline score (on the day of admission), on behalf of the respondents rating score after intervention (the day before discharge), and then suitable patients according to two standards were selected and the difference $d$ between two measuring points was computed. If the patient's anchor overall health improves, then $d=$; if the patient's anchor overall health deteriorates, then $d=-$. The mean of the difference of all patients selected was as the MCID.

\section{Roc Curve Method}

Both the anchor-based method and the distribution-based method have some disadvantages, therefore, Crosby et al. [14] plead for a combination of anchor-based and distribution-based methods to take advantage of both an external criterion and a measure of variability. We call this method as ROC curve method for it is on the basis of ROC curve and anchor-based MIC distribution in nature [15].

First, using an anchor, the patients were divided into two groups: one grade difference/at least one grade difference, no change. Then the distribution of the change in scores on the health status instrument was plotted.

Second, the cut-off point for an MIC was chosen. Here two cut-off points were considered: the Receiver Operating Characteristic (ROC) cut-off point and the $95 \%$ limit cut-off point. The ROC cut-off point is the value for which the sum of percentages of false positive and false negative classifications ([1-sensitivity] + [1specificity]) is smallest. The $95 \%$ limit cut-off point is based on the distribution of scores of these persons who are unchanged according to the anchor.

Next, using the $95 \%$ limit cut-off point, MIC for improvement is defined as the $95 \%$ upper limit of the distribution of scores of these persons who are unchanged according to the anchor [mean change +1.645 $\mathrm{SD}_{\text {changel }}$. Note that the $95 \%$ limit cut-off point corresponds with $95 \%$ specificity on the ROC curve.

To determine the ROC cut-off point for each change in domain score, the sensitivity and specificity were calculated. To construct the ROC curve, the combination of sensitivity and 1-specificity for each change in domain scores was plotted. The MIC, defined as the optimal cut-off point, is found on the ROC curve at the 
point closest to the upper-left corner (i.e. where the sum of the percentages of misclassified patients is lowest).

\section{Multiple Linear Regression Models}

Angst et al. [23] in 2017 has put forward a MCID method by multiple linear regression model, with its advantage adjusting the potential confounding factors. The specific steps are as follows:

First, variables analyzed were determined by anchor options and also potential influence factors. The score change after treatments "' was used as the dependent variable, and the classification group by anchor adopting two kinds of standards "one grade difference" and "at least one grade difference", and potential influence factors such as gender, age, level of education, family economic etc. were used as independent variables.

Second, multivariate linear regression models were built and the parameters and the predictive value of the mean were estimated by SPSS. The multivariate linear regression model was $=a_{0} \square a_{1} x_{1} \square a_{2} x_{2} \rrbracket \ldots a_{k} x_{k \rrbracket}$ Where $x_{1 \rrbracket}$ $\mathrm{x}_{2 \mathbb{8}} \mathrm{x}_{3 \mathbb{8}} \mathrm{x}_{4 \mathbb{8}} \mathrm{x}_{58} \mathrm{x}_{6}$ represents gender, age, level of education, family economic, category, baseline points, respectively, and $a_{1}, a_{2} \ldots a_{6}$ is the partial regression coefficient of with $x_{1 \rrbracket} x_{2 \rrbracket} x_{3 \rrbracket} x_{4 区} x_{5 \nabla} x_{6}$, respectively.

After $a_{1}, a_{2} \ldots a_{6}$ estimated, the predictive value of the mean ( ie. MCID) can be calculated, and also its $95 \%$ confidence interval can be estimated.

Based on the empirical comparison of two different criteria and these anchor methods of ROC curve and multiple linear regression model, a reasonable calculation of MCID for the esophageal cancer scale (QLICPES) was carried out.

\section{Results}

\section{Socio-demographic characteristics of the sample}

The total sample included 232 cases of hospitalized patients with esophageal cancer aged 35 years to 82 years (median age $=60$ years and mean age $=59.3 \pm 8.9$ years). $204(87.9 \%)$ were male and $203(87.5 \%)$ were of Han ethnicity. 139 (59.9\%) have a fair perceived income. On education level, 81 cases (34.9\%) finished primary school, while 129 (55.6\%) completed high school, and 22 (9.5\%) had a college or postgraduate degree.

220 patients (94.8\%) completed the questionnaires at discharge (about four weeks follow-up) and the data were used for computing score change for each patient.

\section{Correlation Coefficients Of Q29 With Domains Of The Qlicp-es}

According to Pearson correlation analysis, the correlation coefficients of Q29 and other domains were all Loading [MathJax]/jax/output/CommonHTML/fonts/TeX/fontdata.js 1 in detail), except for the correlation coefficients of 
Q29 and psychological function of 0.17 . In other words, Q29 could be used as a subjective anchor to calculate the MCID in all domains of the esophageal cancer scale.

Table 1

Correlation coefficients between Q29 and domains of the QLICP-ES

\begin{tabular}{|c|c|c|c|c|c|c|c|}
\hline Item & PHD & PSD & SOD & SSD & SPD & CGM & TOT \\
\hline Q29 & $0.69^{\star \star}$ & $0.17^{*}$ & $0.32^{\star \star}$ & $0.56^{\star \star}$ & $0.68^{\star \star}$ & $0.68^{\star \star}$ & $0.75^{\star \star}$ \\
\hline
\end{tabular}

\section{Mcid By Anchor-based Method}

When Q29 was taken as the subjective anchor, 55 patients had no change in anchor option after interventions, 102 patients had a change with difference of one grade, and 165 patients had a change with difference of at least one grade. As can be seen from Table 2, the mean score changes are positive except of psychological function, and the MCID value obtained by the standard of "at least one grade difference" (standard B) is larger than that obtained by the standard of "one grade difference" (standard A). No matter standards, the MCID value of physiological function was larger than that of the other domains, ranging from 4 to 10 .

Table 2

The MCID of QLICP-ES (V2.0) determined by anchor-based method $\left(n_{A}=102, n_{B}=165\right)$

\begin{tabular}{|c|c|c|c|c|c|}
\hline Domain & Items & $\begin{array}{l}\text { Standard A } \\
- \\
\text { |varvecx } \pm \text { |varvecs }\end{array}$ & $\begin{array}{l}\text { Standard B } \\
- \\
\text { |varvec } x \pm \mid \text { varvecs }\end{array}$ & $\begin{array}{l}\text { Standard } \\
\text { A MCID }\end{array}$ & $\begin{array}{l}\text { Standard } \\
\text { B MCID }\end{array}$ \\
\hline $\begin{array}{l}\text { Physical domain } \\
\text { (PHD) }\end{array}$ & 8 & $15.1 \pm 14.8$ & $19.3 \pm 16.1$ & 15.1 & 19.3 \\
\hline $\begin{array}{l}\text { Psychological } \\
\text { domain (PSD) }\end{array}$ & 9 & $-4.4 \pm 11.8$ & $-4.2 \pm 12.4$ & 4.4 & 4.2 \\
\hline $\begin{array}{l}\text { Social domain } \\
\text { (SOD) }\end{array}$ & 8 & $3.1 \pm 10.2$ & $4.8 \pm 11.2$ & 3.1 & 4.8 \\
\hline $\begin{array}{l}\text { Common } \\
\text { symptoms and } \\
\text { side effect domain } \\
\text { (SSD) }\end{array}$ & 7 & $6.7 \pm 10.7$ & $7.7 \pm 11.3$ & 6.7 & 7.7 \\
\hline $\begin{array}{l}\text { Core/general } \\
\text { module (CGM) }\end{array}$ & 32 & $4.8 \pm 6.5$ & $6.5 \pm 7.3$ & 4.8 & 6.5 \\
\hline $\begin{array}{l}\text { Specific domain } \\
\text { (SPD) }\end{array}$ & 16 & $8.5 \pm 8.3$ & $9.5 \pm 9.2$ & 8.5 & 9.5 \\
\hline Total (TOT) & 48 & $6.0 \pm 6.0$ & $7.5 \pm 6.8$ & 6.0 & 7.5 \\
\hline
\end{tabular}




\section{Mcid By Roc Curve Method}

The sample size of ROC curve method is different from that of the anchor-based method, which includes patients who had no change in anchor option after interventions. Therefore, in the ROC curve method, the sample size of standard $A$ is 157 , and that of standard $B$ is 220 . The area under ROC curve (AUC) and MCID values of all domains of the QLICP-ES in each standard are shown in Table 3, Fig. 1 and Fig. 2, with Fig. 1 and Fig. 2 showing the ROC curves of each domain for standard A and standard B, respectively. As can be seen from Table 3, the MCID values obtained by ROC curve method are consistent and relatively stable under the two standards, except for the psychological function and the specific module, the MCID values.

Table 3

The MCID of QLICP-ES (V2.0) determined by ROC curves $\left(n_{A}=157, n_{B}=220\right)$

\begin{tabular}{|lllll|}
\hline Domain & $\begin{array}{l}\text { Standard } \\
\text { A }\end{array}$ & $\begin{array}{l}\text { Standard } \\
\text { B }\end{array}$ & $\begin{array}{l}\text { Standard A } \\
\text { MCID }\end{array}$ & $\begin{array}{l}\text { Standard B } \\
\text { MCID }\end{array}$ \\
\hline Physical domain (PHD) & AUC & & \\
\hline Psychological domain (PSD) & 0.82 & 0.86 & 7.8 & 7.8 \\
\hline Social domain (SOD) & 0.41 & 0.41 & 9.7 & 5.6 \\
\hline $\begin{array}{l}\text { Common symptoms and side effect } \\
\text { domain (SSD) }\end{array}$ & 0.69 & 0.72 & 4.7 & 4.7 \\
\hline Core/general module (CGM) & 0.71 & 0.73 & 3.6 & 3.6 \\
\hline Specific domain (SPD) & 0.79 & 0.83 & 4.3 & 4.3 \\
\hline Total (TOT) & 0.76 & 0.78 & 2.3 & 7.0 \\
\hline
\end{tabular}

\section{Mcid By Multiple Linear Regression Models}

Table 4 presented the MCID values and regression models for different domains of the scale in standard $\mathrm{A}$, as well as the $P$ values and $R^{2}$ of the models. Among them, the assignment of variables is as follows: the score difference between two measuring points, $x 1$ : gender(male $=0$, female $=1)$, x2:age $(\leqq 60=0,>60=1)$, x3:education (Primary $=1$, middle $=2$, high or technical secondary school $=3$, junior college $=4$, bachelor degree or above $=5$ ), $x 4$ :family economy (poor $=1$, medium $=2$, rich $=3)$, x5:group (no change $=0$, Change a level $=1$ ), $x 6$ :baseline score of domains. The assignment of variables in Standard B is almost the same as standard $A$ except for $x 5$ : group (no change $=0$, change by more than one level $=1$ ). 
Table 4

The MCID of QLICP-ES (V2.0) determined by Multiple linear regression in standard A $\left(\mathrm{n}_{\mathrm{A}}=157\right)$

\begin{tabular}{|c|c|c|c|c|}
\hline Domain & MCID & $P$ & $R^{2}$ & Multiple linear regression model \\
\hline PHD & 9.0 & $<0.001$ & 0.27 & $=-15.46-2.81 x_{1}+1.01 x_{2}-1.21 x_{3}+4.05 x_{4}+16.37 x_{5}+0.13 x_{6}$ \\
\hline PSD & 3.0 & 0.027 & 0.05 & $=-5.60+3.24 x_{1}-0.14 x_{2}+0.67 x_{3}-2.86 x_{4}-2.51 x_{5}+0.12 x_{6}$ \\
\hline SOD & 1.2 & $<0.001$ & 0.12 & $=3.72-1.36 x_{1}-0.61 x_{2}-0.25 x_{3}+3.81 x_{4}+4.42 x_{5}-0.17 x_{6}$ \\
\hline SSD & 4.0 & $<0.001$ & 0.22 & $=24.16+3.24 x_{1}-1.13 x_{2}-0.62 x_{3}-0.06 x_{4}+6.65 x_{5}-0.29 x_{6}$ \\
\hline CGM & 2.6 & $<0.001$ & 0.22 & $=9.07+0.90 x_{1}+0.08 x_{2}-0.28 x_{3}+1.53 x_{4}+5.38 x_{5}-0.18 x_{6}$ \\
\hline SPD & 5.9 & $<0.001$ & 0.12 & $=3.13+1.26 x_{1}+0.50 x_{2}-0.35 x_{3}+0.90 x_{4}+7.23 x_{5}-0.04 x_{6}$ \\
\hline TOT & 3.7 & $<0.001$ & 0.22 & $=3.86+0.93 x_{1}+0.27 x_{2}-0.33 x_{3}+1.13 x_{4}+6.23 x_{5}-0.08 x_{6}$ \\
\hline \multicolumn{5}{|c|}{ 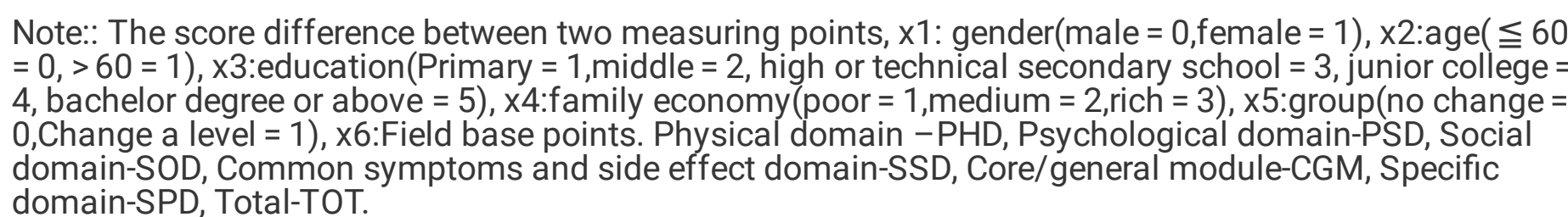 } \\
\hline
\end{tabular}

Table 5 presented the MCID values and regression models for different domains of the scale in standard $\mathrm{B}$, as well as the $P$ values and $R^{2}$ of the models. It can be seen that the MCID value obtained by this method is similar to that of the traditional anchor method. Moreover, the MCID value obtained by standard $B$ is larger than that obtained by standard $A$. 
Table 5

The MCID of QLICP-ES (V2.0) determined by Multiple linear regression in standard B $\left(\mathrm{n}_{\mathrm{B}}=220\right)$

\begin{tabular}{|c|c|c|c|c|}
\hline Domain & MCID & $P$ & $R^{2}$ & Multiple linear regression model \\
\hline PHD & 13.9 & $<0.001$ & 0.36 & $=-26.36-0.03 x_{1}-0.73 x_{2}-0.38 x_{3}+1.62 x_{4}+19.76 x_{5}+0.35 x_{6}$ \\
\hline PSD & 3.3 & 0.002 & 0.07 & $=-13.37+0.08 x_{1}+0.22 x_{2}+0.63 x_{3}-2.10 x_{4}-1.72 x_{5}+0.21 x_{6}$ \\
\hline SOD & 3.0 & 0.002 & 0.07 & $=-7.83+0.71 x_{1}-0.66 x_{2}-0.46 x_{3}+1.45 x_{4}+6.53 x_{5}+0.06 x_{6}$ \\
\hline SSD & 5.6 & $<0.001$ & 0.13 & $=15.90+1.39 x_{1}-0.48 x_{2}+0.20 x_{3}-0.79 x_{4}+8.57 x_{5}+0.20 x_{6}$ \\
\hline CGM & 4.5 & $<0.001$ & 0.18 & $=1.53+1.07 x_{1}-0.63 x_{2}+0.08 x_{3}+0.50 x_{4}+7.72 x_{5}-0.05 x_{6}$ \\
\hline SPD & 7.4 & $<0.001$ & 0.12 & $=-2.42+0.79 x_{1}+0.18 x_{2}-0.26 x_{3}+0.43 x_{4}+7.92 x_{5}+0.04 x_{6}$ \\
\hline TOT & 5.5 & $<0.001$ & 0.21 & $=-1.25+0.98 x_{1}-0.33 x_{2}-0.05 x_{3}+0.43 x_{4}+7.91 x_{5}+0.01 x_{6}$ \\
\hline \multicolumn{5}{|c|}{ 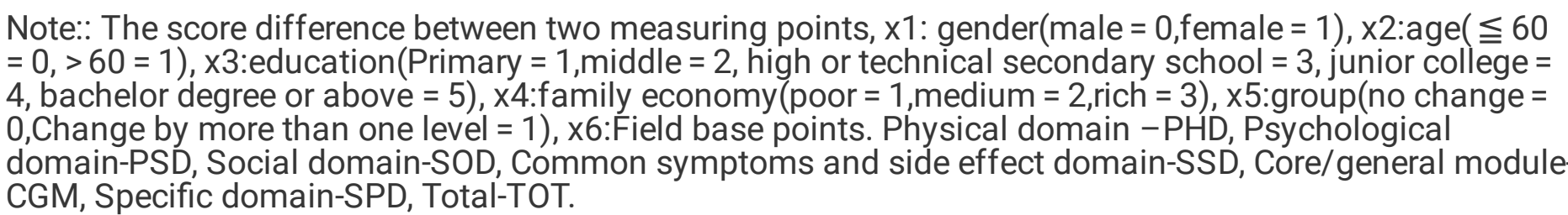 } \\
\hline
\end{tabular}

\section{Discussions}

Currently, there is no international gold standard for the formulation of MCID, anchor-based and distributionbased methods are often used for development of MCID. Relevant literature [24-26] points out that MCID calculated by anchoring should be taken as the main method. Xu et al. [27] obtained the weighted MCID of anchor method, ES method in distribution method or two methods through SPSS simulation. In the anchorbased method, internationally recognized comprehensive scales such as SF-36 and St. George's Breathing Questionnaire (SGRQ) are commonly used as anchors. It can also be seen that the mean values of the two anchors were selected as MCID [28].

In this study, anchor-based method, ROC curve method and the multiple linear regression models were used for both two standards, providing a basis for selecting the appropriate MCID.

First of all, the correlation coefficients between Q29 and various domains are mostly higher than 0.30 , showing a strong correlation. Therefore, Q29 can be used as a subjective anchor.

In terms of the two standards, the MCID obtained from standard B is slightly larger than that from standard A, but standard A "one grade difference" can reflect the minimum clinical difference directly. In terms of the three methods, MCID value ranked as follows: anchor-based $>$ ROC curve $>$ multiple linear regression model, and the two standards of ROC curve method produced almost the same MCID.

Anchor-based method is a traditional and widely used method, which can verify the significance of changes Loading [MathJax]/jax/output/CommonHTML/fonts/TeX/fontdata.js feelings [29]. However, it also has many problems, 
such as determination of suitable anchor, calculation of the difference between positive and negative values, selection of mean and median according to scores distributions, the appropriateness of using clinical objective indicators as objective anchors, and so on [30,31].

The ROC curve method integrates the anchor-based method and the distribution-based method. The area under the ROC curve shows the rationality of the selected anchors, the AUC of this study is basically above 0.7 , indicating a good effect. The MIC corresponding sensitivity and specificity are visualized, increasing the precision and accuracy of the MID estimation. The ROC approach integrates type-one and type-two errors and lie within reasonable limits, and it is suitable for data that is not normally distributed [32, 33]. But the $\mathrm{MIC}_{\mathrm{ROC}}$ is very sensitive to random sampling variation, especially in relatively small samples, and the whole queue data is not used. It is difficult to identify the cut-off point with the best sensitivity and specificity at one glance in the ROC curve. Therefore, Terluin [34] introduced an alternative to the ROC-based MIC, based on predictive modeling.

Multiple linear regression model as an extension of the average change method, opens a new field of vision. $R^{2}$ in this study was lower, possibly because some independent variables had little effect on dependent variables although the model was significant with all $P$ values being less than 0.05 . It's less bias for adjustment or control the MCID of confounding factors. Furthermore, this model can be extended by covariables that may causes confusion and may not be equally distributed between the transition categories, for example, sex, age[23].

The similarity between the multiple linear regression model and the ROC curve method is that the sample sizes of standard A and B are the same. The difference is that multiple linear regression models use basic patient information and can generate $95 \%$ confidence intervals to predict the individual mean and the population mean, while the ROC curve method can increase the precision and accuracy of the MCID estimation.

All methods using anchors to calculate MCID have some similarities and highlights. The advantage is that anchors can be used to give professional explanations, while the disadvantage is that it is difficult to find suitable anchors, and there may be some differences between values produced by different anchors, and the measurement error is ignored [35]. Besides, the traditional anchor-based method is simple and widely used, the ROC curve method is relatively stable, and the multiple regression model can control confounding factors. Therefore, different standards and methods should be selected according to the research purpose and sample characteristics.

In addition to the above methods, some other methods are gradually studied and used, such as Logistic regression model, response cumulative distribution function and so on. They can be also used to calculate MCID for the scale of QLICP-ES in the future.

To sum up, the different methods produce different MCID values. A lot of different MCID values were presented so that it can be easy and convenient to select by users in this paper. Despite all this, in consideration of compromise and stability, the recommended MCID values of physical domain, psychological domain social domain common svmotom and side-effects domain, the specific domain and the overall were Loading [MathJax]/jax/output/CommonHTML/fonts/TeX/fontdata.js

Page 10/16 
7.8, 9.7, 4.7, 3.6, 4.3, 2.3 and 2.9, respectively. Obviously, it was calculated according to ROC curve method under standard $\mathrm{A}$.

\section{Conclusions}

Different methods have their own advantages and disadvantages, and also different definitions and standards can be adopted according to research purposes and methods. In this paper, a lot of different MCID values were presented so that it can be easy and convenient to select by users. The purpose of this study is to provide the basis for selecting the appropriate MCID formulation method. As a hot and difficult problem, MCID needs to be studied further.

\section{Declarations}

\section{Acknowledgements}

In carrying out this research project, we have received substantial assistance from Prof. Gary Lyman from Hutchinson Institute for Cancer Outcomes Research, and Prof. David Cella, Benjamin J. Arnold and Hiramatsu Toshiko at the Center on Outcomes, Research, and Education (CORE), and many staffs at the third affiliated hospital of Kunming Medical University (Yunnan Tumor Hospital), and Sun Yat-sen University Cancer Center. We sincerely acknowledge all the support.

\section{Funding}

This study is supported by the National Natural Science Foundation of China $(71974040,81273185)$, the Features Innovative Projects of Key Platform and Major Scientific Research Project of Universities in Guangdong Province(2016KTSCX046, 2017KZDXM040).

\section{Availability of data and materials}

Not applicable.

\section{Authors' contributions}

CHW, GFL designed the study. DDR, TW, YBQ, JDZ and JYF performed the data collection. DDR, TW performed data analyses and drafted the manuscript. CHW revised the manuscript deeply. All authors contributed to interpreting the data, and have read and approved the final manuscript.

\section{Ethics approval and consent to participate}

The study protocol and the informed consent form were approved by the IRB (institutional review board) of the affiliated hospital of Guangdong Medical University (PJ2012052, YJYS2019010). The respondents were voluntary and provided written consent for participation.

\section{Consent for publication}




\section{Competing interests}

The authors declare that they have no competing interests.

\section{Author details}

1School of Humanities and Management, Research Center for Quality of Life and Applied Psychology, Guangdong Medical University, Dongguan 523808, CHINA.

2The Third Affiliated Hospital of Kunming Medical University( Yunnan Tumor hospital), Kunming 650106, CHINA.

3The Center for Response and Management of Emergence Public Health Event, the Center for Disease Control and Prevention of Yunnan Province, Kunming 650022, CHINA.

4Department of Thoracic Surgery, State Key Laboratory of Oncology in South China, Sun Yatsen University Cancer Center, Collaborative Innovation Center of Cancer Medicine, Guangzhou 510060, CHINA.

\section{References}

1. Brooks JA, Kesler KA, Johnson CS, Ciaccia D, Brown JW. Prospective analysis of quality of life after surgical resection for esophageal cancer: preliminary results. J Surg Oncol. 2002;81(4):185-94.

2. Qiao YL. An important milestone in the epidemiological study of esophageal cancer. Chin J Clin Oncol. 2016;43(12):500-1.

3. Chen W, Zheng R, Baade PD, Zhang S, Zeng H, Bray F, Jemal A, Yu XQ, He J. Cancer statistics in China, 2015. CA Cancer J Clin. 2016;66(2):115-32.

4. Zhang SW, Zheng RS, Zuo TT, Zeng HM, Chen WQ, He J. Mortality and survival analysis of esophageal cancer in China. Chin J Oncol. 2016;38(9):709-15.

5. Sun H, Xie Y, Li JS. Application of minimal clinically important difference in quality of life assessment tools for COPD patients. Chinese General Practice. 2015;(23):2826-2829.

6. Jaeschke R, Guyatt GH, Keller J, Singer J. Interpreting changes in quality-of-life score in $\mathrm{N}$ of 1 randomized trials. Control Clin Trials. 1991;12(4 Suppl):226S-233S.

7. van der Roer N, Ostelo RW, Bekkering GE, van Tulder MW, de Vet HC. Minimal clinically important change for pain intensity, functional status, and general health status in patients with nonspecific low back pain. Spine (Phila Pa 1976). 2006;31(5):578-82.

8. Beaton DE. Understanding the relevance of measured change through studies of responsiveness. Spine (Phila Pa 1976). 2000;25(24):3192-9.

9. Barrett B, Brown D, Mundt M, Brown R. Sufficiently important difference: expanding the framework of clinical significance. Med Decis Making. 2005;25(3):250-61.

10. Copay AG, Subach BR, Glassman SD, Polly DW Jr, Schuler TC. Understanding the minimum clinically important difference: a review of concepts and methods. Spine J. 2007;7(5):541-6. 
11. Wyrwich KW, Bullinger M, Aaronson N, Hays RD, Patrick DL, Symonds T, Clinical Significance Consensus Meeting Group. Estimating clinically significant differences in quality of life outcomes. Qual Life Res. 2005;14(2):285-95.

12. Revicki D, Hays RD, Cella D, Sloan J. Recommended methods for determining responsiveness and minimally important differences for patient-reported outcomes. J Clin Epidemiol. 2008;61(2):102-9.

13. Jayadevappa R, Cook R, Chhatre S. Minimal important difference to infer changes in health-related quality of life-a systematic review. J Clin Epidemiol. 2017;89:188-98.

14. Crosby RD, Kolotkin RL, Williams GR. Defining clinically meaningful change in health-related quality of life. J Clin Epidemiol. 2003;56(5):395-407.

15. de Vet HC, Ostelo RW, Terwee CB, van der Roer N, Knol DL, Beckerman H, Boers M, Bouter LM. Minimally important change determined by a visual method integrating an anchor-based and a distribution-based approach. Qual Life Res. 2007;16(1):131-42.

16. Coeytaux RR, Kaufman JS, Chao R, Mann JD, Devellis RF. Four methods of estimating the minimal important difference score were compared to establish a clinically significant change in Headache Impact Test. J Clin Epidemiol. 2006;59(4):374-80.

17. Terluin B, Eekhout I, Terwee CB. The anchor-based minimal important change, based on receiver operating characteristic analysis or predictive modeling, may need to be adjusted for the proportion of improved patients. J Clin Epidemiol. 2017;83:90-100.

18. Barrett B, Brown D, Mundt M, Brown R. Sufficiently important difference: expanding the framework of clinical significance. Med Decis Making. 2005;25(3):250-61.

19. Wan CH, Yang Z, Meng Q, Feng CY, Wang HY, Tang XL. Development and Validation of the General Module of the System of Quality of Life Instruments for Cancer Patients (QLICP-GM). Int J Cancer. 2008;122(1):190-6.

20. Yang Z, Luo JH, Meng Q, Li GF, Li XJ, Ding YL, Wan CH. Development and Validation of the System of Quality of Life Instruments for Cancer Patients: Head and Neck Cancer (QLICP-HN). Oral Oncol. 2012;48(8):737-46.

21. Wan CH, Meng Q, Yang Z, Tu X, Feng CY, Tang XL. Validation of the Simplified Chinese Version of EORTC QLQ-C30 from the Measurements of Five Types of in Patients with Cancer. Ann Oncol. 2008;19(12):2053-60.

22. Lydick E, Epstein RS. Interpretation of quality of life changes. Qual Life Res. 1993;2(3):221-6.

23. Angst F, Aeschlimann A, Angst J. The minimal clinically important difference raised the significance of outcome effects above the statistical level, with methodological implications for future studies. J Clin Epidemiol. 2017;82:128-36.

24. Norman GR, Sridhar FG, Guyatt GH, Walter SD. Relation of distribution- and anchor-based approaches in interpretation of changes in health-related quality of life. Med Care. 2001;39(10):1039-47.

25. Clinical Significance Consensus Meeting Group Sprangers MA, Moinpour CM, Moynihan TJ, Patrick DL, Revicki DA. Clinical Significance Consensus Meeting Group. Assessing meaningful change in quality of life over time: a users' guide for clinicians. 
26. Yuksel S, Ayhan S, Nabiyev V, Domingo-Sabat M, Vila-Casademunt A, Obeid I, Perez-Grueso FS, Acaroglu E, European Spine Study Group (ESSG). Minimum clinically important difference of the health-related quality of life scales in adult spinal deformity calculated by latent class analysis: is it appropriate to use the same values for surgical and nonsurgical patients? Spine J. 2019;19(1):71-8.

27. Xu QA, Zhang CM, Wan $\mathrm{CH}$, Yang Z, Xu CZ, Chen Y. Computer simulation of MCID method for calculating minimum clinical significance. Chinese Journal of Health Statistics. 2017;34(5):785-7.

28. Xue HH, Yang Z, Wan CH, Xu QA, Xu CZ, Chen Y. A minimum clinical important differential value (MCID) based on scale score was developed. Chinese Journal of Health Statistics. 2019;36(03):436-40.

29. Brozek JL, Guyatt GH, Schunemann HJ. How a well-grounded minimal important difference can enhance transparency of labelling claims and improve interpretation of a patient reported outcome measure. Health Qual Life Outcomes. 2006;4:69.

30. Coon CD, Cook KF. Moving from significance to real-world meaning: methods for interpreting change in clinical outcome assessment scores. Qual Life Res. 2018;27(1):33-40.

31. Yang Z. Development of the General Module of the system of Quality of Life Instruments for Cancer Patients (V2.0) and Estimation of its Minimal Clinically Important Difference. Southern Medical University. 2015.

32. Kemmler G, Zabernigg A, Gattringer K, Rumpold G, Giesinger J, Sperner-Unterweger B, Holzner B. A new approach to combining clinical relevance and statistical significance for evaluation of quality of life changes in the individual patient. J Clin Epidemiol. 2010;63(2):171-9.

33. Wells G, Beaton D, Shea B, Boers M, Simon L, Strand V, Brooks P, Tugwell P. Minimal clinically important differences: review of methods. J Rheumatol. 2001;28(2):406-12.

34. Terluin B, Eekhout I, Terwee CB, de Vet HC. Minimal important change (MIC) based on a predictive modeling approach was more precise than MIC based on ROC analysis. J Clin Epidemiol. 2015;68(12):1388-96.

35. Crosby RD, Kolotkin RL, Williams GR. Defining clinically meaningful change in health-related quality of life. J Clin Epidemiol. 2003;56(5):395-407.

\section{Figures}




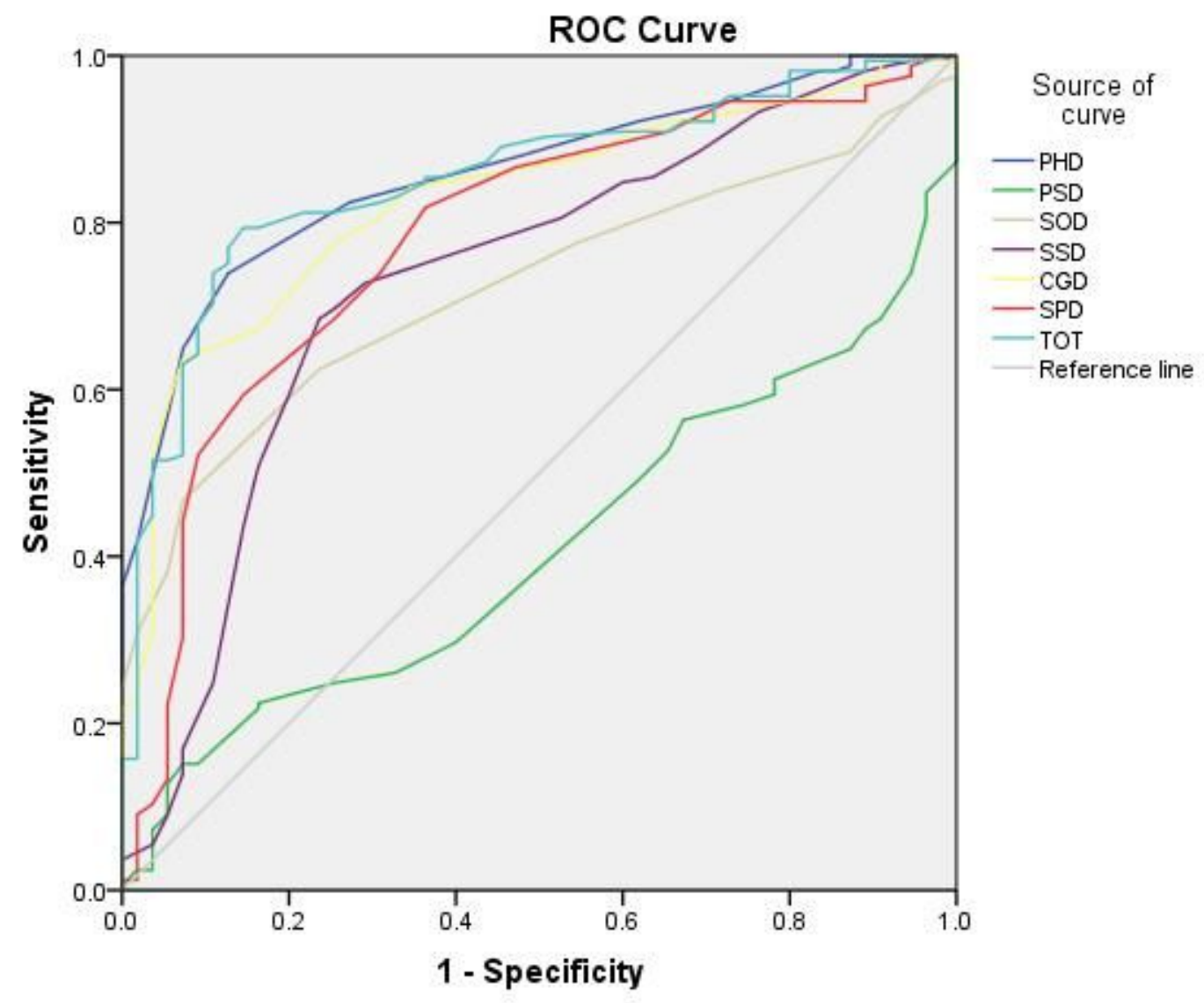

由结生成的对角线段。

Figure 1

ROC curve of the group with no change and the group with change of at least one grade difference 


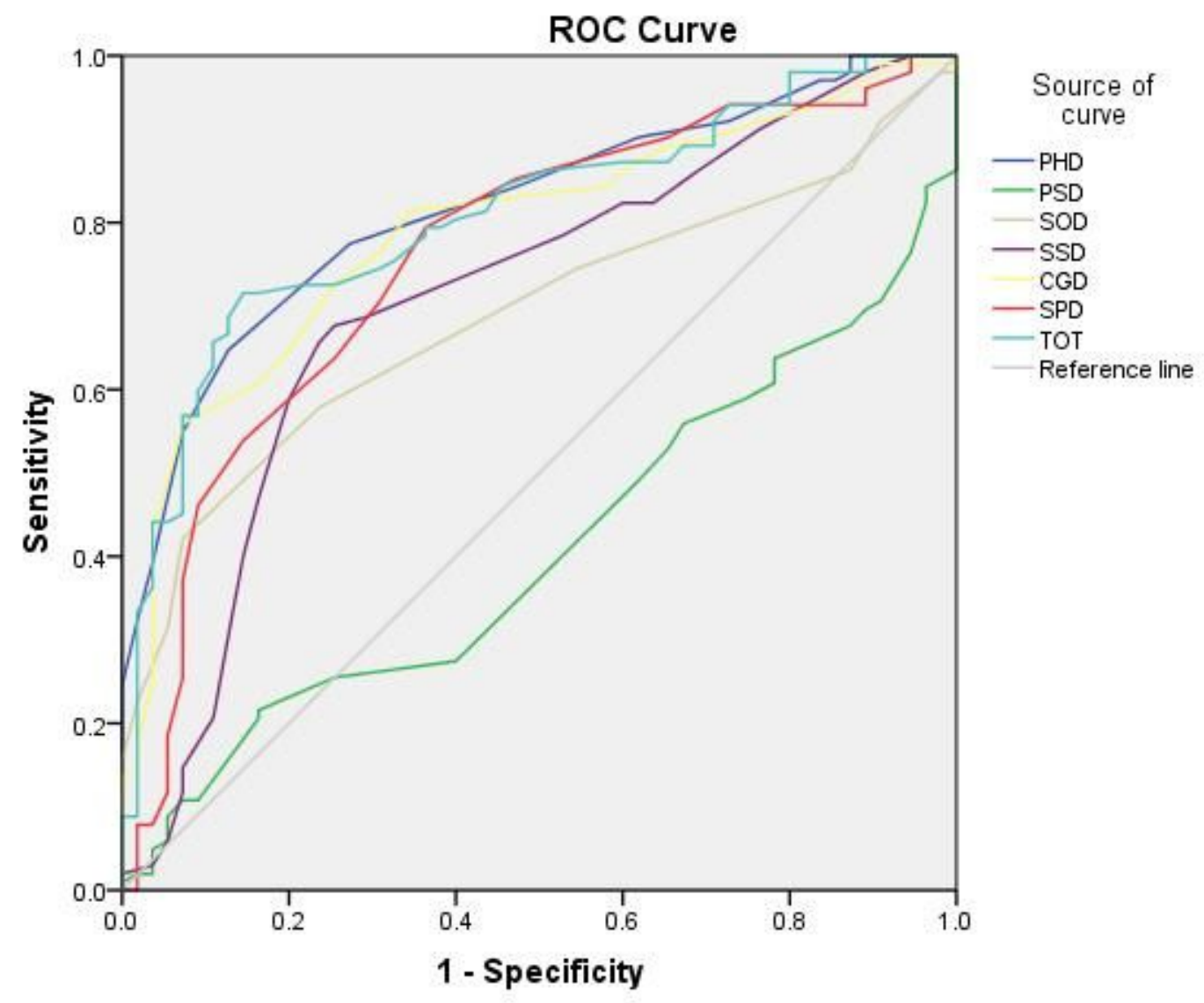

由结生成的对角线段。

\section{Figure 2}

ROC curves of the group with no change and the group with change of one grade difference 